\title{
Brincadeiras de faz-de-conta em crianças autistas: limites e possibilidades numa perspectiva evolucionista
}

\author{
Carla Silva Fiaes \\ Ilka Dias Bichara \\ Universidade Federal da Bahia
}

\begin{abstract}
Resumo
A constatação da presença universal da brincadeira na infância sugere que tal comportamento deva ter grande valor adaptativo para a espécie. Apesar de universal, a brincadeira sofre interferência do estado desenvolvimental do indivíduo. Crianças com autismo, por exemplo, apresentam dificuldades no brincar, o que nos leva a questionamentos sobre a natureza da sua brincadeira simbólica, se todo faz-de-conta necessariamente inclui teoria da mente e porque um fenômeno considerado universal surge de modo tão atípico no autismo. $\mathrm{O}$ artigo discute essas questões à luz da psicologia evolucionista, ilustrando relatos de brincadeiras espontâneas de crianças autistas coletados em instituições educacionais na cidade de Salvador (BA). Os resultados sugerem que os episódios de faz-de-conta envolvem freqüentemente a presença de objetos como apoio para o desenvolvimento da brincadeira. Tal fato está em acordo com a descrição de alguns autores sobre o desenvolvimento do faz-de-conta, com seu início mais sustentado por objetos e independente de metarepresentação.
\end{abstract}

Palavras-chave: brincadeira; autismo; psicologia evolucionista; teoria da mente.

\begin{abstract}
Make-Believe play in autistic children: constraints and possibilities in the evolutionary perspective. The universal presence of play into the infancy suggests that this behavior must to have a great value adaptative to specie. Although universal, the play receive interference of developmental degree, as children with autism. The difficulties presented by autistic children on the play have came questions about the nature of symbolic play, if all make-believe include theory of mind and why a phenomenon universal emerge of differentiated way in the autism. The article discuss this questions to view of evolutionary psychology, illustrating relates of autistic children's spontaneous play collecting in educational institutions in the Salvador's City. The results suggests that the make believe episodes involves the presence of objects as supportive to developmental of the play. This fact is in accord with the description of some authors about the make-believe developmental, with the start more sustained for objects and independent of metarepresentation.
\end{abstract}

Keywords: play; autism; evolutionary psychology; theory of mind.

A brincadeira, considerada um fenômeno universal na infância, tem sido postulada na atualidade, como uma das características definidoras desta fase. De fato, a observação cotidiana de crianças revela que elas freqüentemente convertem quase toda atividade em brincadeira. Entretanto, entre crianças com desenvolvimento atípico, a brincadeira emerge de forma diversa, especialmente entre aquelas portadoras de transtornos globais do desenvolvimento, onde os próprios critérios diagnósticos incluem a identificação de algum comportamento disruptivo na brincadeira, como falta de reciprocidade social, ausência de jogos ou brincadeiras de imitação social e pobreza ou inexistência de brincadeiras simbólicas espontâneas (American Psychiatric Association, 2002; Organização Mundial de Saúde, 2003).

A investigação da brincadeira espontânea de crianças autistas em diferentes contextos de seu cotidiano tem nos levado a questionamentos acerca do modo atípico com que se expressam tais brincadeiras como, por exemplo, se existe ou não faz-de-conta, se todo faz-de-conta necessariamente inclui teoria da mente, entre outros.

Também, considerando-se que as principais dificuldades enfrentadas por indivíduos autistas localizam-se na área da sociabilidade, coloca-se a questão: por que um fenômeno considerado universal, a saber, a brincadeira, surge de modo tão distorcido no autismo?

Para responder essas e outras questões, buscaremos, neste artigo, discutir os principais conceitos envolvidos, dialogando criticamente com a literatura pertinente sob o ponto de vista evolucionista e, ao fazer isso, relatar alguns episódios colhidos em pesquisa desenvolvida pelas autoras utilizando a observação 
de brincadeiras espontâneas de crianças autistas em instituições educacionais especiais e regulares na cidade de Salvador (BA).

\section{A brincadeira como comportamento adaptativo}

A constatação da presença universal da brincadeira na infância sugere que tal comportamento deva ter grande importância para o desenvolvimento das crianças. Os principais teóricos da área de desenvolvimento trataram do tema, propondo distintas funções à brincadeira, que pode refletir, resultar ou reforçar o desenvolvimento da criança, a depender da abordagem adotada (Johnson, Christie, \& Yawkey, 1999).

Apesar de deter o interesse das mais variadas áreas de investigação quanto à sua funcionalidade (Psicologia, Antropologia, Sociologia, Educação, etc.), definir o que é brincadeira tem sido uma tarefa árdua e os resultados, em geral, não são conclusivos, isto porque, "brincar" inclui uma ampla variedade de atividades e nenhuma delas sozinha é representativa do fenômeno exclusivamente. Por esse motivo, no intuito de auxiliar a identificação da brincadeira e distingui-la de outros fenômenos com os quais costuma ser confundida, tais como exploração, curiosidade e comportamento estereotipado, Burghardt (2005) propôs um grupo de cinco critérios identificadores da brincadeira, compatíveis com a visão evolucionista do desenvolvimento, como um modo de sintetizar as características mais centrais do fenômeno, que não se restringe apenas à espécie humana. São eles: 1) função imediata limitada; 2) comportamento intrinsecamente motivado; 3) diferença temporal ou estrutural; 4) ocorrência repetida; e 5) em ambiente relaxado.

Esses critérios são úteis porque salientam a distinção entre um comportamento que é realizado repetidamente de forma similar (brincadeira) daquele que é estereotipado rigidamente. Além disso, considera que a criança teria uma tendência a brincar de forma relativamente independente de estimulações ou motivações externas, pelo prazer que a brincadeira proporciona, desde que o ambiente seja seguro o suficiente para permitir que o comportamento seja expresso. Por fim, os critérios sugerem que a brincadeira pode não ter resultados observáveis a curto prazo.

Os teóricos que adotam a perspectiva evolucionista defendem que o brincar possui uma função adaptativa evidenciada pela ampla presença nas diversas espécies de mamíferos e pelos seus padrões semelhantes de expressão. Tal fato sugere uma unidade filogenética e funcional em resposta a pressões evolutivas semelhantes que as espécies enfrentaram para a sobrevivência (Yamamoto \& Carvalho, 2002).

Dentre os mamíferos, aqueles que mais brincam são também os que precisam exibir, na vida adulta, maior flexibilidade comportamental e habilidades especializadas com maior nível de complexidade para caçar, lutar, subir em árvores, viver em grupos sociais e utilizar instrumentos (Bichara, Lordelo, Carvalho, \& Otta, 2009). O tempo estendido da infância, protegida pelos adultos, parece favorecer a aquisição dessas habilidades através da experimentação e aprendizagem. Neste sentido, a brincadeira seria um meio importante de treinar, na ausência de grandes perigos, as atividades que serão necessárias para a fase adulta.

As demandas do passado evolutivo tornaram a espécie humana a mais lúdica dentre os primatas. Dentro desta perspectiva, esse tempo estendido pode ser considerado como um momento importante para o amadurecimento de determinadas estruturas e funções do organismo e a brincadeira teria papel fundamental neste desenvolvimento.

Para Pellegrini, Dupuis e Smith (2007), a brincadeira durante o período de imaturidade humana representa um exemplo paradigmático de um comportamento nos níveis ontogenético e filogenético. Em termos filogenéticos, o Homo Sapiens é considerado uma espécie neotênica, pois os bebês humanos nascem de forma relativamente precoce e os indivíduos adultos preservam características físicas semelhantes aos dos indivíduos jovens. Além disso, a espécie humana possui uma infância bastante estendida em relação aos demais primatas, o que lhe possibilita um tempo maior de experimentação através da brincadeira. Ou seja, em conseqüência à relativa prematuridade do bebê humano, a criança nasce com poucas habilidades completamente desenvolvidas. Entretanto, a posse de um cérebro relativamente grande e o tempo longo da infância, habilitam o indivíduo a explorar recursos do ambiente e, conseqüentemente, a aprender os meios necessários para a própria sobrevivência.

Assim, indivíduos que tiveram mais oportunidades para experimentar na infância através do brincar, podem alcançar a fase adulta com mais habilidades que o auxiliarão a sobreviver em ambientes de grandes perigos e de poucos recursos, características presentes no ambiente de adaptação evolutiva. Considerando-se que a sobrevivência de uma espécie se dá através da seleção de indivíduos e não de grupos, os indivíduos melhor adaptados ao ambiente tendem a gerar mais descendentes, que herdam tais capacidades.

Portanto, a brincadeira que ocorre durante o período juvenil foi um comportamento selecionado, não para a sobrevivência na cultura moderna, mas pelo seu valor adaptativo no ambiente evolucionário. Sendo assim, uma característica que foi adaptativa para nossos ancestrais poderia não ter utilidade para os humanos contemporâneos, mas permanecer presente, desde que não fosse suficientemente prejudicial a ponto de resultar em extinção da espécie, ou caso tivesse um impacto neutro na evolução, não interferindo no seu potencial reprodutivo (Bjorklund, 1997). No entanto, as considerações acerca do papel da brincadeira na infância contemporânea sugerem a existência de fatores positivos para a espécie na atualidade.

Em relação à ontogenia, a brincadeira é observada desenvolvendo-se de forma regular em termos de idade de aparecimento e declínio. Assim, por exemplo, todas as formas de brincadeira são precedidas pela exploração (Pellegrini \& Smith, 1998), seguidas de brincadeiras que são qualitativamente diferentes ao longo do tempo até que começam a surgir comportamentos que são aparentemente similares aos de um adulto. Tais comportamentos são tipicamente exagerados e, possivelmente, possuem importância para o desenvolvimento subseqüente (Pellegrini et al., 2007).

Apesar dos benefícios para a fase adulta serem bastante reconhecidos por boa parte dos estudiosos do desenvolvimento infantil, estudos recentes na área, compatíveis com a idéia de que a infância não é apenas um período preparatório para a fase adulta, mas uma fase importante em si, e que certas tarefas 
desenvolvimentais possuem funções específicas durante certos períodos da história de vida, têm considerado que a brincadeira possui benefícios a curto prazo (Bjorklund, 1997; Pellegrini \& Bjorklund, 2004; Pellegrini et al., 2007; Pellegrini \& Smith, 1998). Dessa forma, alguns aspectos da brincadeira podem ser preparatórios para as demandas físicas, sociais e cognitivas particulares do ambiente da própria infância (Bjorklund, 1997).

A hipótese de que a brincadeira tem efeitos imediatos e não apenas retardados baseia-se, basicamente, em duas premissas: a primeira assume que o trabalho de seleção natural não se restringe apenas aos efeitos para a maturidade; e a segunda que, para um comportamento ser selecionado, os benefícios associados devem ser maiores que os custos (Pellegrini et al., 2007).

Sendo assim, embora a brincadeira possa ser custosa em termos de dispêndio calórico, de tempo e de riscos para a sobrevivência (como a exposição do sujeito a predadores), os benefícios associados têm implicações importantes para a função e possível seleção natural do comportamento. Ou seja, a brincadeira é um comportamento funcional porque os benefícios associados superam os seus custos (Pellegrini \& Bjorklund, 2004) e, provavelmente, possuem tanto efeitos retardados para a maturidade, como efeitos imediatos durante o período juvenil.

Atualmente os benefícios imediatos da brincadeira têm ganhado destaque, especialmente porque as vantagens para o desenvolvimento posterior podem não ser evidentes, haja vista que o desenvolvimento apresenta descontinuidades. Em acordo com este pensamento, Pellegrini et al. (2007) mencionam como principal benefício a curto prazo da brincadeira a geração de comportamentos e estratégias inovadoras, especialmente na brincadeira social. Pellegrini e Smith (1998) também enumeram como benefícios imediatos a boa forma física, possibilitada pela brincadeira motora; as habilidades de luta e dominância desenvolvida nas brincadeiras turbulentas; e as habilidades afiliativas e de teoria da mente, que se desenvolvem principalmente nas brincadeiras social e simbólica.

Por outro lado, ao invés de brincar, algumas dessas habilidades poderiam ser adquiridas de modo mais direto, através de treino. Entretanto, as crianças permanecem brincando apesar dos riscos e desperdício energético, o que sugere que o prazer produzido na brincadeira consiste em um forte motivador que não deve ser desconsiderado.

Tais considerações acerca da importância da brincadeira na ontogenia sugerem que o estudo deste fenômeno no autismo possa trazer informações importantes para a compreensão de como estão relacionados aspectos críticos do desenvolvimento infantil, tais como o amadurecimento de habilidades sociais, de capacidades cognitivas e comunicativas a partir da investigação de como esses comportamentos se expressam no brincar de crianças que têm graves prejuízos nas áreas de interação social, comunicação e imaginação.

\section{O autismo à luz da Psicologia Evolucionista}

A Psicologia Evolucionista considera que, de modo semelhante às características físicas, as capacidades cognitivas e emocionais e seus comportamentos correspondentes evoluíram em função de problemas de relevância adaptativa.
De acordo com Luz e Bussab (2009), a prevalência na população de transtornos que comprometem o desempenho dos indivíduos para atividades mínimas de sobrevivência aparentam comprometer as idéias darwinistas de aptidão para a sobrevivência e reprodução, entretanto, tal idéia não corresponde à realidade. Doenças e psicopatologias têm sido alvo da atenção de psicólogos evolucionistas, que as consideram como respostas desproporcionais ou inadequadas às demandas pela sobrevivência, ou como resultantes de permutas adaptativas que tiveram vantagens colaterais.

Para melhor compreender como tem sido concebido o processo de constância de doenças, especialmente, de psicopatologias ao longo do processo evolutivo, torna-se necessário caracterizar alguns termos importantes, tais como doença, patologia, sintoma, e vantagens colaterais.

Os termos doença, saúde e patologia têm sido tratados classicamente de modo comparativo, em relação à média da população, sendo a normalidade entendida a partir de um prisma estatístico e saúde como a prontidão para o funcionamento normal (Luz \& Bussab, 2009). A patologia, por sua vez, corresponderia a uma disfunção no funcionamento que levaria a um quadro de insuficiência para manutenção das funções vitais.

Em termos evolutivos, a eleição dos sinais e sintomas como unidade de funcionamento dos organismos configura-se como mais útil do que o uso do termo "doença", porque os sintomas possuem grande valor de defesa para o organismo, enquanto a doença, em si, corresponde à manifestação de uma série de sintomas, que podem ser comuns a muitas outras doenças (Luz \& Bussab, 2009). Assim, sintomas como febre, dor e inchaço, funcionariam como mecanismos de defesa que foram selecionados ao longo da evolução para serem estratégias associadas ao aumento de sobrevivência no ambiente de adaptação evolutiva.

O questionamento sobre a função de um determinado sintoma conduz à busca dos sistemas comportamentais que lhes possam dar subsídios em uma explicação de tipo evolucionista. De acordo com Luz, Brüne e Bussab (2004), os "sistemas funcionais" correspondem a comportamentos que foram moldados pela seleção natural e de cuja eficácia a espécie depende para sobreviver. Uma vez identificado o sistema e constatada sua funcionalidade, trata-se de investigar os fatores determinantes nos níveis próximos e últimos.

O nível de causalidade próxima do fenômeno refere-se ao valor adaptativo imediato, em termos de ontogênese e de causação imediata, que pode ser satisfatório ou não. Já a causalidade última corresponde à evolução do processo psicológico em questão no ambiente de adaptabilidade evolutiva, que resultou em traços adaptativos e não adaptativos. É no nível último que se deve procurar um sistema funcional que lhe esclareça a ocorrência, considerando as circunstâncias em que tais traços poderiam ser adaptativos (Luz, Brüne, \& Bussab, 2004). Como é sabido, o processo de seleção, geralmente, ocorre de modo bastante lento e gradual, o que justifica, de certo modo, a persistência de traços não adaptativos nos dias atuais.

As estratégias de seleção e adaptação dos organismos ao meio devem levar em consideração a equação de custos e benefícios. Luz e Bussab (2009) chamam atenção para o que 
eles denominam complexo co-adaptado, no qual a perpetuação de um traço limitante deve ser observada a partir do organismo como um todo, pois há características que trazem tanto prejuízos quanto benefícios. Dessa forma, a noção de eficiência adaptativa, segundo esses autores, é relativa, considerando-se as causas próximas e últimas.

Em relação aos distúrbios psicopatológicos, Brüne e BrüneCohrs (2006) propõem que a ausência e o empobrecimento na capacidade de inferir estados mentais próprios e de outros indivíduos, conhecida como "teoria da mente", podem estar subjacentes a muitos deles, como nas psicopatias, nos distúrbios afetivos, na esquizofrenia e nos danos e distúrbios degenerativos cerebrais. Entretanto, é nos distúrbios do espectro autista que se concentram as maiores discussões acerca da falha do desenvolvimento da teoria da mente.

De acordo com os autores supracitados, essa capacidade teria papel central na vida humana, porque, do ponto de vista evolucionista, a inteligência, incluindo a teoria da mente, teria evoluído para facilitar a detecção de trapaceiros e reforçar a cooperação. Considerando-se que primatas, de modo geral, e a espécie humana, de modo mais extremo, vivem em grupos sociais nos quais o sucesso na interação social resulta em vantagens no compartilhamento de alimento, na distribuição de recursos e na conquista de parceiros sexuais, faz sentido conceber que qualquer disfunção nesta capacidade cognitiva poderia provocar danos ao funcionamento social.

Distúrbios na teoria da mente têm sido freqüentemente usados para explicar os sintomas comportamentais em crianças com espectro autista, pois as suas falhas no estabelecimento de relacionamentos emocionais, a evitação de contatos visual e corporal e o uso de recursos lingüísticos de modo anormal ou empobrecido, sugerem um empobrecimento em apreciar estados mentais em outros indivíduos, mesmo que outras capacidades cognitivas estejam intactas (Brüne \& Brüne-Cohrs, 2006; Leslie, 1987). Em contrapartida, crianças com atraso cognitivo significativo, como portadores de Síndrome de Down, demonstram melhor desempenho em ações que evidenciam teoria da mente, como atenção compartilhada (Brown \& Whiten, 2000) e tarefas de falsas crenças (Frith \& Frith, 1999), do que crianças autistas, até quando situações do dia-a-dia são usadas, como no reconhecimento de emoções complexas e estados mentais em contextos sociais (Golan, Baron-Cohen, \& Golan, 2008).

Algumas hipóteses têm tentado justificar os motivos que levaram à possível falha na teoria da mente de indivíduos autistas. A teoria do cérebro masculino extremo, por exemplo, toma por base as pressões seletivas relativas ao cuidado parental e as demandas por reprodução, que ao longo do processo evolutivo resultaram em diferenças comportamentais entre machos e fêmeas. Essa teoria defende que o autismo seria um extremo das diferenças típicas do sexo masculino em termos de sistematização e da capacidade de ter empatia (Baron-Cohen, Wheelwright, Lawson, Griffin, \& Hill, 2008).

Falhas no sistema dos neurônios-espelho, responsáveis pelo reconhecimento da ação, pela imitação e empatia, também têm sido associados às causas do autismo (Lameira, Gawryszewski, \& Pereira Jr, 2006). De acordo com Oberman e Ramachandran (2007), mecanismos de simulação interna, como os neurônios espelhos, são necessários para o desenvolvimento da imitação, do reconhecimento, da teoria da mente, da empatia e da linguagem, sendo assim, disfunções nesses mecanismos podem estar subjacentes aos déficits comunicativos observados em indivíduos autistas.

\section{Teoria da mente, brincadeira de faz-de-conta e au- tismo}

A ausência de Teoria da Mente em crianças autistas tem sido utilizada também para justificar o empobrecimento de suas brincadeiras de faz-de-conta. A quase totalidade dos estudos tem encontrado uma menor freqüência de brincadeiras simbólicas entre crianças autistas (Blanc, Adrien, Roux, \& Barthélémy, 2005; Brown \& Whiten, 2000; Libby, Powell, Messer, \& Jordan, 1998; Tamanaha, Chiari, Perissinoto, \& Pedromônico, 2006), dando margem a algumas propostas de trabalhos que estimulem o faz-de-conta nessas crianças (Keen, Rodger, Doussin, \& Braithwaite, 2007; Sherrat, 2002; Yang, Wolfberg, Wu, \& Hwu, 2003). Segundo Leslie (1987), é nesse tipo de brincadeira que emergem as mais precoces manifestações da habilidade de caracterizar e manipular informações relativas aos estados mentais próprios e dos outros.

Nas brincadeiras de faz-de-conta, simbólicas ou fantasiosas, a criança trata os objetos como se fossem outros, podendo atribuir propriedades diferentes das que eles realmente possuem, ou atribuir a si e aos outros, papéis diferentes dos habituais, criando cenas imaginárias e representando-as (Morais \& Otta, 2003). Apesar de haver certa variedade na nomenclatura e nas definições desse tipo de brincadeira, de modo geral, compreendese que há a substituição de uma coisa por outra, quer seja ela um objeto (como tratar uma boneca como se fosse um bebê) ou um papel (como uma criança tratar a si como um professor e a outra criança como seu aluno).

De acordo com Pellegrini e Bjorklund (2004), a brincadeira de faz-de-conta tem um caráter essencialmente social, o que implica a função imediata de ajudar crianças mais jovens a tomar a perspectiva de outros brincantes.

Estudos sobre entendimento de falsas crenças têm encontrado que, de modo geral, crianças a partir de 4 a 5 anos compreendem que cada mente representa o mundo em uma variedade de formas. O mesmo tipo de solução parece estar presente na brincadeira de faz-de-conta porque enquanto finge algo, a criança é capaz de entender que uma coisa que está representando algo do mundo pode, na realidade, ser outra (por exemplo: um telefone de plástico de brinquedo representa um aparelho que permite duas pessoas se comunicarem à distância).

Por conceber que a realização de brincadeira simbólica envolveria a representação de estados mentais, alguns autores defendem que ela seja limitada apenas aos humanos, o que implicaria uma descontinuidade filogenética. Alternativamente, alguns teóricos têm proposto que a brincadeira de faz-de-conta não envolve necessariamente metarepresentação (Lillard, 2001; Pellegrini \& Bjorklund, 2004) e que alguns macacos, especialmente chimpanzés, seriam capazes de realizar algumas transformações simbólicas em suas brincadeiras. Washoe, o primeiro chimpanzé treinado em linguagem, por exemplo, banhava, ensaboava e secava bonecas (Gardner \& Gardner, 1969), 
de forma semelhante como o fazem as crianças pequenas.

Lillard (2001) realizou uma revisão de alguns estudos que tomam por premissa o modelo da metarepresentação e concluiu que as evidências empíricas não o apóiam. Outros modelos são revisados, culminando na proposta do modelo Twin Earth, que propõe relações específicas entre a brincadeira de faz-deconta mais simples e o entendimento mental, até a emergência mais tardia do jogo de papéis e a representação mental. Esse modelo sugere que o mundo imaginado pela criança durante o faz-de-conta é, em muitos aspectos, semelhante ao mundo real, sendo apenas determinadas circunstâncias modificadas, como a areia que se torna uma torta de maçã ou a boneca que ganha vida. O mais central nessa teoria é que o faz-de-conta permite a participação e o raciocínio da criança sobre situações não presentes.

Pellegrini e Bjorklund (2004), por sua vez, assumem a “Teoria da Simulação" de Harris (1995), que dá conta de explicar como crianças menores de três anos engajam-se no faz-deconta. De acordo com essa teoria, inicialmente essas crianças assumem que suas simulações na brincadeira são as mesmas que as dos seus colegas, mas com a repetição de encontros para brincadeira, elas reconhecem que muitas vezes suas perspectivas e estados mentais diferem dos outros. Assim, com o decorrer do tempo, elas passam a pôr suas crenças e desejos de lado e a imaginar, temporariamente, o de seus pares, usando suas próprias funções mentais para apreciar o que os outros sentem ou pensam. De acordo com Pellegrini e Bjorklund (2004), nesse período, entender o ponto de vista do outro depende da acurácia da simulação e não da natureza da representação.

É só depois da maturação e de repetidas interações com os outros que as crianças, por volta dos 5 anos, começam a compreender os estados mentais alheios. Assim, crianças jovens e chimpanzés não têm uma teoria da mente, mas reconhecem que os outros vêem os mesmos objetos de modo diferente deles. Tal fato parece encontrar apoio no uso que alguns animais fazem de sinais para anunciar aos outros que a sua ação é uma brincadeira (por exemplo: uso da face de brincadeira em primatas), o que sugere que eles reconhecem que seus co-específicos podem ter uma visão diferente da situação (Pellegrini \& Bjorklund, 2004).

A partir dessas novas perspectivas, torna-se possível conceber que crianças autistas possam apresentar algum tipo de brincadeira simbólica ainda que não façam uso de metarepresentação. Assim, com o objetivo de descrever os possíveis padrões de desenvolvimento da brincadeira simbólica dessas crianças, selecionamos alguns episódios observados em contextos educacionais (regular e especial) e que fazem parte de uma investigação mais ampla a respeito do brincar de crianças autistas.

\section{Método}

\section{Participantes}

Os participantes deste trabalho foram cinco crianças autistas, sendo quatro meninos e uma menina, dois deles irmãos gêmeos, todos na faixa etária de 4 a 9 anos. As características desenvolvimentais apresentadas pelos participantes são diversas, com aquisição da linguagem verbal e escrita diferenciada entre os indivíduos. Tal fato não constitui exceção ao universo autista, pois este grupo apresenta sintomas e formas de expressão amplamente variados, embora algumas características sejam recorrentes, como os comprometimentos na interação social, na comunicação e nos padrões de comportamentos e de atividades restritos e repetitivos. Pode-se afirmar que as subcategorias formadas pelos transtornos globais do desenvolvimento compõem um espectro, que varia num continuum quanto à gravidade.

\section{Situação}

A pesquisa foi desenvolvida em dois tipos de ambientes: o primeiro deles, a instituição especializada no atendimento a crianças autistas, e o segundo, quatro escolas de ensino regular diferentes. Apenas uma das escolas foi alvo de observação por mais de uma vez, pois nela estudavam dois irmãos em salas diferentes.

A escolha pela observação na escola regular justifica-se pela premissa de que em tal contexto, a criança com dificuldades encontra modelos mais avançados de comportamentos para seguir e para interagir do que em escolas especiais e tal fato pode ter interferência na expressão da brincadeira. Por outro lado, as crianças permanecem por pouco tempo na instituição especializada (apenas o suficiente para realizarem as atividades pedagógicas com o professor), não havendo tempo reservado especificamente para sua interação com outras crianças, como ocorre na escola.

\section{Procedimento}

Os dados foram obtidos através da observação direta do comportamento durante o período de brincadeira livre, no qual as crianças desenvolviam suas atividades lúdicas sem o direcionamento de adultos. Foram realizadas três sessões semanais de observação na escola e três na instituição especial para cada criança, com duração de pelo menos 15 minutos, variando conforme os horários de recreação de cada local. As atividades realizadas pelas crianças foram anotadas através da técnica de registro cursivo de comportamento, que consiste em registrar de forma pormenorizada os comportamentos observados numa folha de registro.

\section{Resultados e Discussão}

A fim de delimitar de forma mais precisa os episódios de brincadeiras simbólicas, foram utilizados critérios como pistas faciais e corporais, verbalizações e comportamento motor. Apesar dos sujeitos da pesquisa possuírem um repertório verbal limitado - o que dificulta a identificação dos enredos das brincadeiras -, incluímos nesse item a emissão de vocalizações, gritos e risos. Os movimentos e gestos também auxiliaram na identificação de muitos episódios porque a atividade motora parece ser um meio mais evidente da excitação que a brincadeira provoca na criança. Os pulos constantes durante a brincadeira representaram um exemplo bastante ilustrativo neste sentido.

O episódio a seguir consiste em um exemplo típico da brincadeira de faz-de-conta apresentada pelas crianças, que, 
por sua característica de pouca riqueza e uso limitado de verbalizações, poderia vir a ser definido como uma brincadeira de manipulação de objetos:

João pega um carro, mexe nele em cima da mesa. Vocaliza: "Ih, inh". Mexe o carro em cima da mesa, balança os braços, vocaliza, empurra o carro (...). Sacode o carro na mão (...). Ri. Bate no carro com o dedo. Empurra (...). Empurra o carro em cima da mesa (...). No chão, empurra o carro contra os outros brinquedos, fazendo "Ih, ih", passa pelos outros carros, empurra um avião atrás. Vocaliza. Deita no chão e empurra o avião. Tira os outros brinquedos da frente, passa entre eles (como se fossem obstáculos), empurra o carro contra o avião Empurra o caminhão adiante. Pega o carro, faz "Ih". Empurra o avião e o carro.

Este episódio reflete algumas das características das brincadeiras de faz-de-conta encontradas: limitadas freqüentemente ao uso de objetos, com gestos e verbalizações escassos, que dificultam a criação de enredos mais elaborados. Como afirmam Pellegrini e Bjorklund (2004), a complexidade da brincadeira de faz-de-conta está relacionada à facilidade lingüística para a manutenção da interação entre pares e compartilhamento dos episódios. Além disso, a linguagem consiste em um dos meios utilizados para identificar cenas de faz-de-conta entre crianças pequenas, pois elas costumam realizar mudanças no tom de voz durante a brincadeira (Bichara, 1994).

A dependência da presença de objetos para a ocorrência do faz-de-conta também parece encontrar apoio em alguns achados anteriores acerca do desenvolvimento da brincadeira simbólica. De acordo com Fein (1981), a brincadeira de faz-de-conta segue um curso desenvolvimental na direção de um aumento de independência do estímulo que está imediatamente presente para uma maior dependência de esquemas mentais (imaginativos), sugerindo que a criança adquire progressivamente a capacidade de simbolizar em modos mais complexos com o decorrer do tempo. Assim, por exemplo, as brincadeiras dependentes do objeto são características de crianças até a idade de dois anos; a partir de então a criança realiza transformações via substituição de um objeto por outro, seguidas de transformações via animação de um objeto inanimado e assim por diante.

Bering (2001) também propõe uma diferenciação entre a brincadeira simbólica que é dependente das características do objeto da brincadeira simbólica verdadeira. No primeiro tipo, o comportamento imaginativo é dirigido a um objeto que guarda semelhança com outro, enquanto que a brincadeira simbólica verdadeira seria aquela que ocorre independentemente da existência de qualquer estímulo perceptual, ou seja, a criança é capaz de criar enredos mesmo que não exista qualquer tipo de objeto presente. Esse tipo de brincadeira costuma emergir apenas depois do terceiro ano de idade, enquanto o tipo dependente do objeto parece caracterizar as brincadeiras simbólicas observadas em alguns chimpanzés, como no caso citado acima envolvendo o chipanzé Washoe.

No episódio exposto a seguir podemos observar um exemplo de brincadeira bastante associado às características dos objetos, onde o indivíduo apresenta diversos comportamentos estereotipados e repetitivos.

Marcelo vai até o carrinho dos brinquedos, escolhe o avião e traz para a mesa. A professora diz: "Avião, Marcelo". Ele fica empurrando o avião em cima da mesa. Empurra pela ponta do bico do avião até o outro lado da mesa. Vai até o carrinho, traz uma caixa de DVD e empurra. Devolve a caixa para o carrinho, traz um dado, empurra em cima da mesa. Devolve para a caixa; Traz um ovo quebrado de plástico e fica empurrando de um lado para o outro. Pega o avião e fica empurrando. Pega o avião e pula. Aperta a ponta do fundo do avião e pula. Faz isso várias vezes.

Matthews (1977) visando identificar as principais mudanças cognitivas que marcam o início dos episódios de faz-de-conta de crianças de quatro anos de idade encontrou seis modos predominantes de transformação empregados: substituição, atribuição de função, animação, atribuição material a objetos que não existem ou não estão presentes, atribuição a situações que não existem no contexto e atribuição de características de personagens através de representação. Esses modos de transformação simbólica foram agrupados em dois modos principais de transformação, sendo o primeiro, o modo material, no qual as iniciações de brincadeiras fantasiosas são caracterizadas pela atribuição da criança de qualidades estranhas ou não associadas a objetos presentes; e o segundo modo foi denominado de ideacional, pois se refere a idéias ou imagens mentais de coisas que não estão presentes no local.

De acordo com a categorização de Matthews (1977), podemos supor que a maior parte das brincadeiras de fazde-conta apresentadas por crianças autistas pode ser descrita como modo de transformação de atribuição de função, onde se atribui uma propriedade funcional a um objeto que não possui tal propriedade. Neste sentido, a um brinquedo que representa uma miniatura de um objeto real pode ser atribuída a capacidade funcional desse objeto, como por exemplo, imaginar que um carro de brinquedo pode ser dirigido, como no episódio descrito abaixo: "João pega o ônibus pequeno, coloca entre as pernas da Minnie, empurra de um lado para o outro".

Constatamos então, que as brincadeiras de faz-de-conta de crianças com autismo guardam uma grande semelhança ou parecem ser do mesmo tipo daquelas observadas em crianças menores, ainda que outras capacidades desenvolvimentais estejam mais avançadas.

A variedade com que se apresenta o desenvolvimento de crianças autistas é bastante ampla, conforme descrito anteriormente. Se eles possuem teoria da mente, metarepresentação ou qualquer outro tipo de compreensão dos estados mentais alheios é uma questão controversa. Exemplos como o seguinte levantam questionamentos acerca da idéia amplamente difundida de um mundo próprio vivenciado por esses sujeitos. No exemplo abaixo, Leo demonstra atenção à conversa das professoras e que tem conhecimento sobre a existência de Pokemons e que Kio seria o nome de um deles.

Léo pega um brinquedo no carrinho, pergunta o que é. A professora diz que é um pintinho no ovo. Ele bate um urso de plástico e o "ovo" um no outro. Duas outras professoras con- 
versando comentam que o ovo é um Pokemon, chamado Kio. Léo coloca o Pokemon e o urso um do lado do outro. Léo fala "Kio, Pokémon". Coloca um em cima do outro. Bate o urso no Pokemon. Léo com o Pokemon fala "Kio", deita o urso, coloca um do lado do outro, diz: "Pokemon".

Os exemplos aqui relatados ilustram temas de brincadeira evidentemente marcados pela estereotipia de gênero e semelhantes aos de meninos que possuem desenvolvimento típico (brincadeiras de luta e transportes). Segundo Bichara (1994), a maior parte dos estudos de faz-de-conta constatou preferências diferenciadas de meninos e meninas, onde os meninos preferem brincadeiras com muita ação e as meninas, temas domésticos. Entre crianças autistas, apesar do isolamento social típico e da forma do brincar, o conteúdo da brincadeira destaca-se como semelhante ao das demais crianças. Todos os meninos brincaram de temas e objetos associados a transportes como carrinhos, aviões, ou mesmo dados e outros objetos usados como se fossem carrinhos. Já a única menina presente neste estudo apresentou episódios mais independentes de objetos, interagindo freqüentemente com os colegas da escola regular. Os exemplos a seguir ilustram algumas dessas interações:

Mônica entra na sala da brinquedoteca com as crianças. Senta numa mesa sozinha. Escolhe dois cavalos na estante e senta-se na mesa. Coloca um cavalo de frente para o outro e faz eles se baterem. Uma menina aproxima-se, pega um dos cavalos e fala "aqui o cavalinho". A menina e Mônica sacodem os cavalinhos no ar. A menina se afasta. Mônica pega mais 3 animais na estante, senta na mesa. Sacode os cavalos como se estivesse cavalgando. Coloca um cavalo em cima do outro (....). Sacode a zebra como se cavalgasse.

Mônica engatinha atrás de duas meninas no velotrol. Anda ajoelhada. Levanta e corre. Ajoelha. Uma menina se ajoelha, depois outra. Uma delas fala "mamãe, mamãe", junto com as outras no velotrol. Mônica corre e senta em um velotrol vazio. Aproxima-se das meninas e corre. As meninas dizem: "Corre, Mônica". Outras meninas ajoelhadas dizem: "Mamãe";

"Mônica anda pelo parque. Entra na casinha, um menino entra também. Ela coloca a cabeça para fora da janela. Sai da casa. Sopra a casa forte e diz: 'Tá soprando, a casa caiu!'”.

Estes episódios contendo falas da própria criança indicam o quanto a linguagem e os gestos orientam a compreensão do fazde-conta. Em relação aos temas, diferentemente dos meninos, os conteúdos apresentados por Mônica nas brincadeiras foram mais neutros do que tipificados. No entanto, o reduzido número da amostra nos impossibilita fazer generalizações em relação a esses dados. Por outro lado, o estudo de Knickmeyer, Wheelwright e Baron-Cohen (2008), que contou com uma amostra de 20 meninas, encontrou que elas brincaram mais de faz-de-conta e demonstraram significativamente mais interesse por brinquedos de faz-de-conta típicos do seu sexo do que itens neutros ou masculinos em comparação com os meninos, sugerindo que a brincadeira simbólica está mais preservada nelas do que neles.

Isso é bastante interessante, pois mostra a existência de certo grau de identidade dessas crianças com seu próprio gênero, e como dizem Aydt e Corsaro (2003) a mais importante identidade que a criança aprende para definir a si mesma e aos outros é a de gênero.

\section{Considerações finais}

É possível conjecturar, a partir do enfoque evolucionista, que a brincadeira empobrecida de crianças autistas possa ter conseqüências no período desenvolvimental, desde os mais imediatos, como o reforço dos prejuízos típicos do próprio transtorno, bem como efeitos danosos mais distais. Dessa forma, a baixa freqüência de envolvimento em atividades que possibilitam o desenvolvimento dessas habilidades, sendo a brincadeira o principal espaço para tal na infância, possibilita predizer as conseqüências negativas também para o desenvolvimento adulto. Ou seja, os déficits característicos do transtorno prejudicam a aparição do fenômeno (a brincadeira) e, a ausência deste, por sua vez, possivelmente conduz a atrasos no desenvolvimento de habilidades importantes para a adaptação do sujeito numa sociedade complexa.

Entretanto, vale à pena considerar que as descontinuidades no desenvolvimento sugerem que a brincadeira em si pode não ser determinante para o desenvolvimento de todas as habilidades importantes para a vida adulta do sujeito. De forma que alguns indivíduos desenvolvem habilidades em áreas específicas, apesar de apresentarem atrasos globais no comportamento.

Fica evidente a necessidade de mais estudos empíricos, principalmente os que busquem a observação de brincadeiras e interações espontâneas, pois só assim poderemos conhecer melhor os limites e possibilidades de crianças autistas em relação às formas e conteúdos de seus faz-de-conta.

\section{Agradecimentos}

As autoras agradecem a CAPES pela concessão da bolsa de mestrado da primeira autora.

\section{Referências}

American Psychiatric Association (2002). Diagnostic and Statistical Manual of Mental Disorders (4 ${ }^{\mathrm{a}}$ Ed). Washington, DC: American Psychiatric Association Press.

Aydt, H., \& Corsaro, W. A. (2003). Differences in children's construction of gender across cultures. American Behavioral Scientist, 46(10), 1306-1325.

Baron-Cohen, S., Wheelwright, S., Lawson, J., Griffin, R., \& Hill, J. (2008). The exact mind: empathising and systemizing in autism spectrum conditions. In U. Goswami (Org.), Handbook of childhood cognitive development. Blackwell: Oxford.

Bering, J. M. (2001). Theistic percepts in other species: can chimpanzees represent the minds of non-natural agents? Journal of Cognition and Culture, 1 , 101-137.

Bichara, I. D. (1994). Um estudo etológico sobre a brincadeira de faz-de-conta em crianças de 3 a 7 anos. Tese de Doutorado, Instituto de Psicologia da Universidade de São Paulo, São Paulo.

Bichara, I. D., Lordelo, E. R., Carvalho, A. M. A., \& Otta, E. (2009). Brincar ou brincar: eis a questão - a perspectiva da psicologia evolucionista sobre a brincadeira. In E. Otta \& M. E. Yamamoto (Orgs.), Psicologia Evolucionista (pp.104-113). Rio de Janeiro: Guanabara Koogan.

Bjorklund, D. F. (1997). The role of immaturity in human development. 
Psychological Bulletin, 122(2), 153-169.

Blanc, R., Adrien, J. L., Roux, S., \& Barthélémy, C. (2005). Dysregulation of pretend play and communication development in children with autism. Autism, 9(3), 229-245.

Brown, J., \& Whiten, A. (2000). Imitation, theory of mind and related activities in autism: an observational study of spontaneous behaviour in everyday contexts. Autism, 4(2), 185-204.

Brüne, M., \& Brüne-Cohrs, U. (2006). Theory of mind - evolution, ontogeny, brain mechanisms and psychopathology. Revista de Etologia, 6(2), 119-129.

Burghardt, G. M. (2005). Defining play: can we stop playing around? In G. M Burghardt (Org.), The genesis of animal play: testing the limits (pp.45-82). Cambridge: The MIT Press.

Fein, G. G. (1981). Pretend play in childhood: an integrative review. Child Development, 52, 1095-1118.

Frith, C. D., \& Frith, U. (1999). Interacting minds - a biological basis. Science, 286, 1692-1695.

Gardner, R. A., \& Gardner, B. T. (1969). Teaching sign language to a chimpanzee. Science, 165, 664-672.

Golan, O., Baron-Cohen, S., \& Golan, Y. (2008). The 'Reading the Mind in Films' task [Child version]: complex emotion and mental state recognition in children with and without autism spectrum conditions. Journal of Autism and Developmental Disorders, 38, 1534-1541.

Harris, J. R. (1995). Where is the child's environment? A group socialization theory of development. Psychological Review, 102(3), 458-489.

Johnson, J. E. Christie, J. F., \& Yawkey, T. D. (1999). Play and Development. In J. E. Johnson, J. F. Christie, \& T. D. Yawkey (Orgs.), Play and early childhood development (pp. 25-52). New York: Longman.

Keen, D., Rodger, S., Doussin, K., \& Braithwaite, M. (2007). A pilot study of the effects of a social-pragmatic intervention on the communication and symbolic play of children with autism. Autism, 11(1), 63-71.

Knickmeyer, R. C., Wheelwright, S., \& Baron-Cohen, S. B. (2008). Sextypical Play: Masculinization/Defeminization in Girls with an Autism Spectrum Condition. Journal of Autism Developmental and Disorders, 38 , 1028-1035.

Lameira, A. P., Gawryszewski, L. G., \& Pereira Jr., A. (2006). Neurônios espelho. Psicologia USP, 17(4), 123-133.

Leslie, A. M. (1987). Pretense and Representation: the origins of "Theory of Mind". Psychological Review, 94(4), 412-426.

Libby, S.; Powell, S.; Messer, D., \& Jordan, R. (1998). Spontaneous play in children with autism: a reappraisal. Journal of Autism and Developmental Disorders, 28(6), 487-497.

Lillard, A. S. (2001). Pretend play as twin earth: a social-cognitive analysis. Developmental Review, 21, 495-531.

Luz, F., Brüne, M., \& Bussab, V. S. R. (2004). Considerações básicas a respeito da psicopatologia evolucionista. Revista de Etologia, 6(2), 119-129.

Luz, F., \& Bussab, V. S. R. (2009). Psicopatologia evolucionista. In E. Otta, \& M. E. Yamamoto (Orgs.), Psicologia Evolucionista (pp.163-175). Rio de Janeiro: Guanabara Koogan.

Matthews, W. S. (1977). Modes of transformation in the initiation of fantasy play. Developmental Psychology, 13, 212-216.

Morais, M. S., \& Otta, E. (2003). Entre a serra e o mar. In A. M. A. Carvalho, \& C. M. C. (Orgs.), Brincadeira e cultura: viajando pelo Brasil que brinca (vol. 2) (pp. 127-154). São Paulo: Casa do Psicólogo.

Oberman, L. M., \& Ramachandran, V. S. (2007). The simulating social mind: the role of the mirror neuron system and simulation in the social and communicative deficits of autism spectrum disorders. Psychological Bulletin, 133, 310-327.

Organização Mundial de Saúde. (2003). Classificação Estatística Internacional de Doenças e Problemas relacionados à Saúde. São Paulo: Edusp.

Pellegrini, A. D., \& Bjorklund, D. F. (2004). The ontogeny and phylogeny of children's object and fantasy play. Human Nature, 15(1), 23-43.

Pellegrini, A. D., Dupuis, D., \& Smith, P. K. (2007). Play in evolution and development. Evolutionary models of human development. Developmental Review, 27, 261-276.

Pellegrini, A. D., \& Smith, P. K. (1998). The development of play during childhood: forms and possible functions. Child Psychology \& Psychiatry Review, 3(2), 51-57.

Sherratt, D. (2002). Developing pretend play in children with autism: a case study. Autism, 6(2), 169-179.

Tamanaha, A. C., Chiari, B. M., Perissinoto, J., \& Pedromônico, M. R. (2006). A atividade lúdica no autismo infantil. Distúrbios da Comunicação, 18(3), 307-312.

Yang, T-R., Wolfberg, P. J., Wu, S-C., \& Hwu, P-Y. (2003). Supporting children on the autism spectrum in peer play at home and school: Piloting the integrated play groups model in Taiwan. Autism, 7(4), 437-453.

Yamamoto, M. E. \& Carvalho, A. M. A. (2002). Brincar para quê? Uma abordagem etológica ao estudo da brincadeira. Estudos de Psicologia, 7(1), 163-164

Carla Silva Fiaes é mestranda no Programa de Pós-Graduação da Universidade Federal da Bahia, bolsista CAPES. E-mail: csfiaes@yahoo.com.br

Ilka Dias Bichara, doutora em Psicologia Experimental pela Universidade de São Paulo, é professora associada do Instituto de Psicologia da Universidade Federal da Bahia e coordenadora do núcleo de pesquisa "Brincadeiras e Contextos Culturais. E-mail: ilkadb@ufba.br 